\section{Dengue Virus Infection Presenting as Membranoproliferative Glomerulonephritis Type} 1

\author{
Sami Alobaidi ${ }^{1}$, Hamza Bali ${ }^{2}$, Mohammad F. Tungekar ${ }^{3}$, Ahmed Akl 2, 4, 5
}

1. Department of Medicine, University of Jeddah, Jeddah, SAU 2. Department of Medicine, Dr Soliman Fakeeh Hospital, Jeddah, SAU 3. Histopathology, Uranologics Ltd, London, GBR 4. Department of Medicine, Fakeeh College of Medical Sciences, Jeddah, SAU 5. Urology and Nephrology Centre, Mansoura University, Mansoura, EGY

Corresponding author: Sami Alobaidi, salobaidi@uj.edu.sa
Review began 03/25/2021 Review ended 04/02/2021 Published 04/05/2021

\section{() Copyright 2021}

Alobaidi et al. This is an open access article distributed under the terms of the Creative Commons Attribution License CC-BY 4.0., which permits unrestricted use, distribution, and reproduction in any medium, provided the original author and source are credited.
Categories: Pathology, Infectious Disease, Nephrology

Keywords: dengue infection, acute kidney injury, haematuria, proteinuria, membranoproliferative glomerulonephritis

\section{Introduction}

Dengue viral infection (DVI), a mosquito-borne infection caused by virus with four serotypes of the genus flavivirus, has a global footprint [1]. The infection results in a variety of clinical manifestations, from an asymptomatic illness to severe and fatal systemic haemorrhagic disease [1,2]. The risk of severe disease is much higher in secondary rather than primary dengue infection. The involvement of kidneys commonly manifests as acute kidney injury caused by plasma leakage syndrome or myoglobinuria [2,3]. A proportion of cases suffer from haematuria and/or nephrotic range proteinuria, believed to be caused by a 'glomerulonephritic process' that has not been fully pathologically characterised [4]. Membranoproliferative glomerulonephritis (or its synonym mesangiocapillary glomerulonephritis) of immune complex type or type I (MPGN-I) is a form of glomerular injury that has established association with hepatitis B and hepatitis C virus infections [5]. We describe a case of DVI who presented with nephrotic range proteinuria and impaired kidney function that was diagnosed by light, immunofluorescence and electron microscopy as MPGN-I. Complete remission of proteinuria with recovery of renal function was achieved over a period of one year. We report this case to document DVI as yet another viral cause of MPGN-I and describe its successful management after the biopsy diagnosis.

\section{Case Presentation}

A 61-year-old male was admitted to the local hospital in his home town in the Philippines with high-grade fever and haemolytic anaemia with a history of mosquito bites. Intravenous fluids and medications were initiated. Normal serum creatinine and no proteinuria had been recorded one month back on a routine check-up. A diagnosis of DVI was made based on a positive immunoglobulin (Ig)M test for dengue virus. The patient reported no previous history of DVI. On his return to Saudi Arabia, he presented to our out-patient department with significantly elevated blood pressure with his blood pressure readings at 200/100 $\mathrm{mm} \mathrm{Hg}$, generalized anasarca, a painful epigastrium and acute kidney injury with a serum creatinine of $247 \mu \mathrm{mol} / \mathrm{L}$ (that worsened on next day to $265 \mu \mathrm{mol} / \mathrm{L}$ ), proteinuria $14 \mathrm{gms} / 24$ hours, total serum cholesterol 7.78 $\mu \mathrm{mol} / \mathrm{L}$ and serum albumin $29 \mathrm{gm} / \mathrm{L}$. Autoimmune serology (antinuclear antibody (ANA) and antineutrophil cytoplasmic autoantibodies (ANCA) and tests for hepatitis B virus (HBV), hepatitis C virus (HCV), and human immunodeficiency virus (HIV) were negative. Complement levels were low. Urine analysis showed haematuria and leukocyturia. An ultrasound revealed grade I nephropathy and normal-sized kidneys with no pelvicalyceal lesions.

After managing his hypertension and since conservative measures did not produce an improvement in kidney function, a renal biopsy was performed. The biopsy included 16 glomeruli, one of them globally sclerosed (Figure 1). All the perfused glomeruli displayed global endocapillary hypercellularity with lobulated profiles, segmental duplication of basement membranes and polymorphonuclear leukocytes with foci of 


\section{Cureus}

karyorrhexis (Figure 1A). Mild focal tubulointerstitial scarring affecting less than $5 \%$ of the cortex was seen. There was insignificant acute tubular injury and no myoglobin casts. Immunofluorescence microscopy (as seen in Figure $1 B$ ) showed capillary wall and mesangial positivity for IgG and C3 (all 3+) and electron microscopy confirmed subendothelial and mesangial electron dense deposits (Figure 1C). These features were diagnostic of MPGN-l (immune complex type). A regimen of high dose steroids (prednisolone $60 \mathrm{mg}$ per day) and mycophenolate mofetil ( $1 \mathrm{gm}$ twice per day) for one month was decided. A significant improvement in kidney function was achieved with serum creatinine returning to normal $(79.6 \mu \mathrm{mol} / \mathrm{L})$, which was followed by tapering of oral steroids and continuation of mycophenolate mofetil $1 \mathrm{gm}$ twice per day for six months. Proteinuria improved from $14 \mathrm{gm} /$ day to $315 \mathrm{mg} /$ day (then nil) and serum albumin was $4.29 \mathrm{gm} / \mathrm{dl}$ after two months of treatment (Figures 2-3). At follow up, 18 months after discharge, the patient was free of oedema and proteinuria with normal serum creatinine levels. He maintained a normal renal profile at a follow up appointment at one year after discharge.

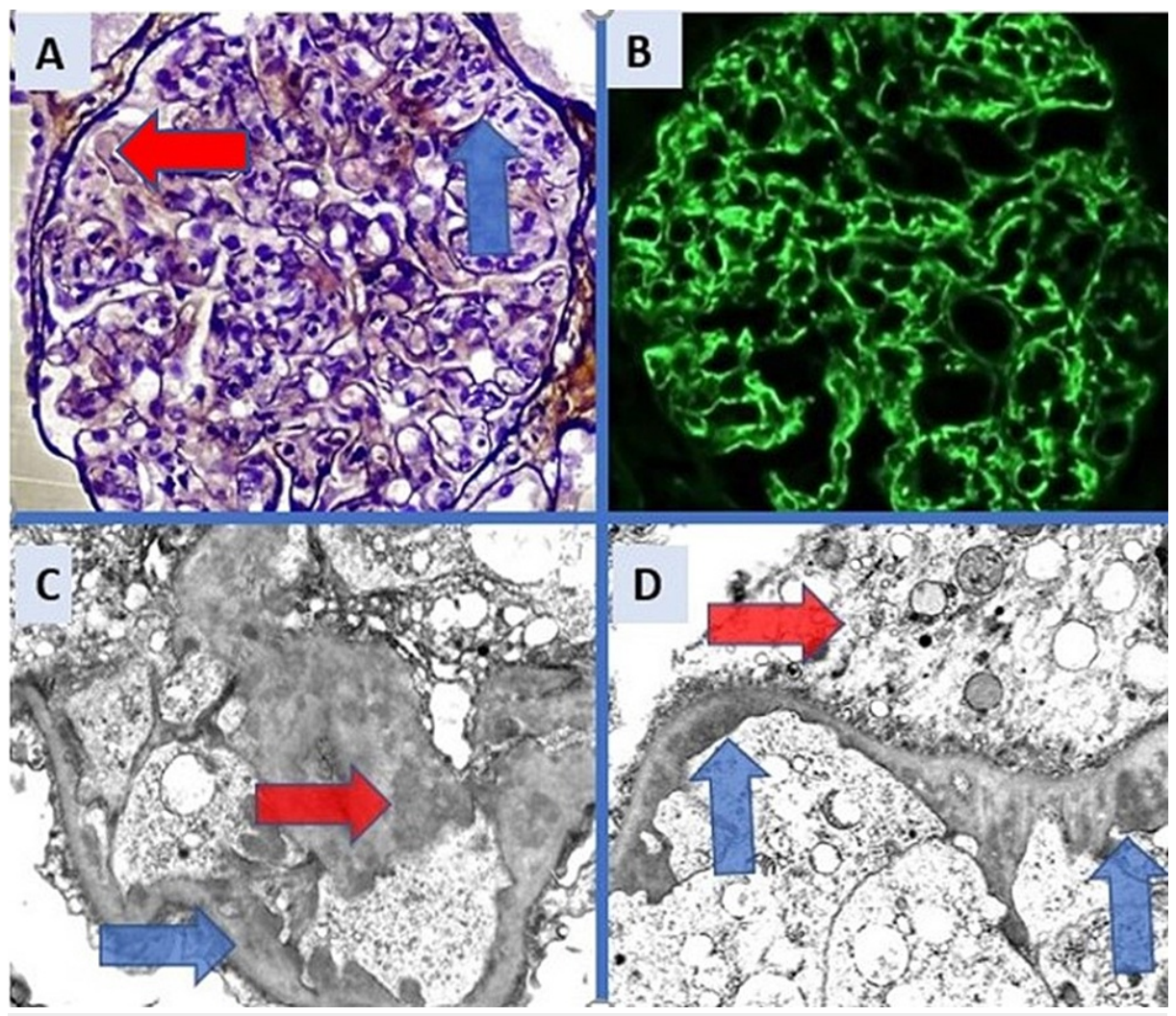

FIGURE 1: Kidney biopsy

A: Glomerulus showing vague lobular profile, intense endocapillary and mesangial hypercellularity, groups of polymorphonuclear leukocytes (blue arrow) and duplication of capillary walls (red arrow). (Jones silver stain, X120), B: Immunofluorescence stain for IgG (X120), C: Electron Micrograph showing subendothelial (blue arrow) and mesangial (red arrow) deposits (X2500), D: Electron micrograph showing more subendothelial deposits (blue arrows) and activated podocyte (red arrow), (X2500). 


\section{Cureus}

Serum Creatinine $(\mathrm{mg} / \mathrm{dl})$

2.5

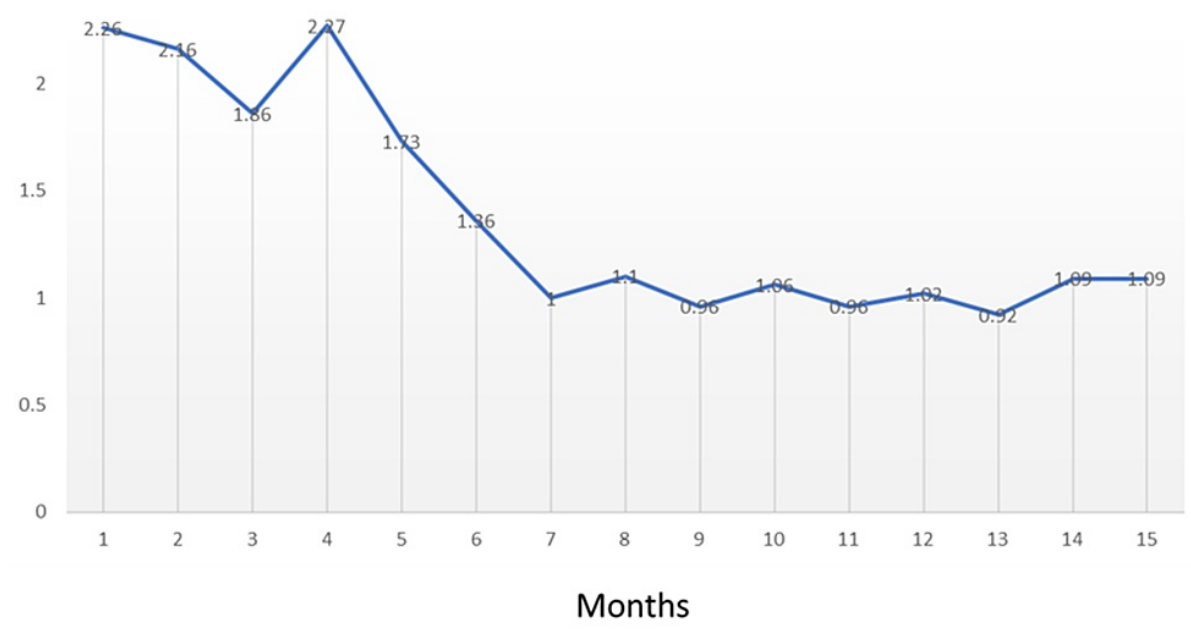

FIGURE 2: Serum creatinine monitoring through follow up time (months)

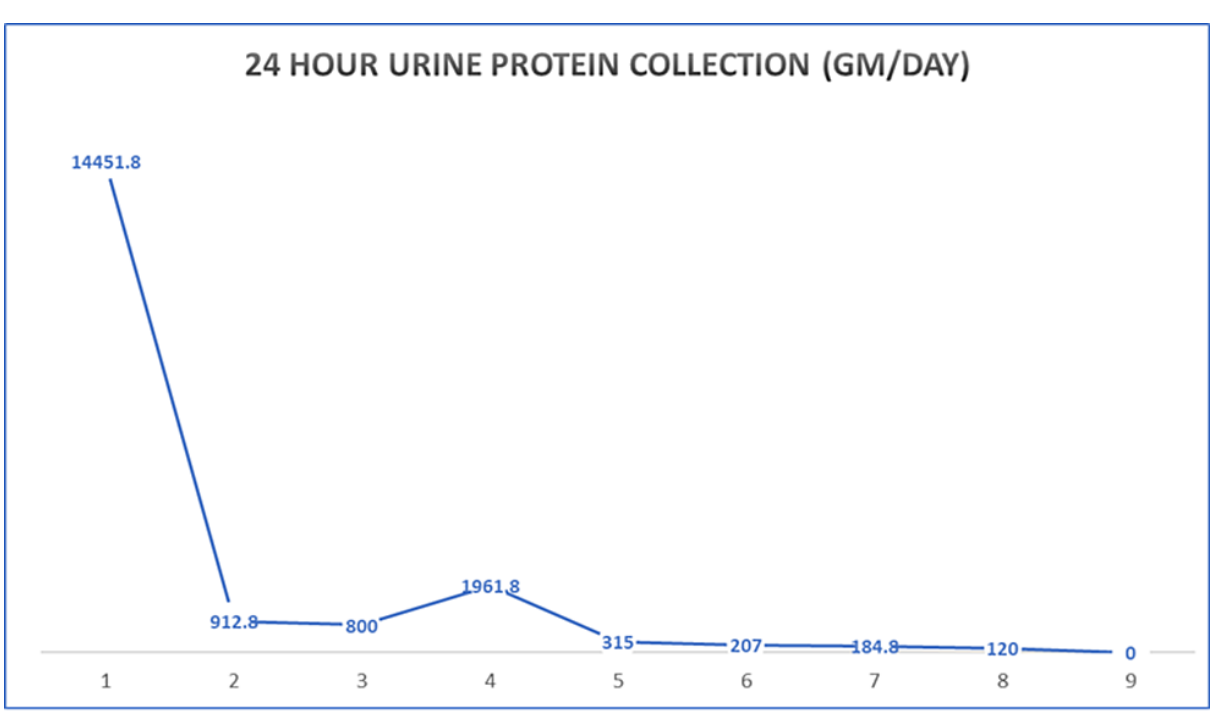

Months

FIGURE 3: Twenty-four hour urine protein collection monitoring through follow up time (months)

\section{Discussion}

The commonly reported renal involvement in DVI is acute tubular injury due to hypovolaemic shock, direct cytopathic effect of the virus on renal tubules, acute thrombotic microangiopathy or damage caused by myoglobinuria [2]. Rarely acute thrombotic microangiopathy is the cause of renal dysfunction [6]. The glomerular disease with significant proteinuria leading to nephrotic syndrome is also encountered and its pathology often described simply as 'proliferative glomerulonephritis' without proper morphological description or classification of the lesion [4]. Some case reports have assumed the presence of glomerular lesions based on findings on urine analysis [7].

The role of immune complexes in causing glomerular injury in human DVI is a subject of debate in the literature although experimental animal studies have confirmed it [8]. Some authors, while acknowledging the formation of immune complexes in DVI, have either ruled out or raised the possibility of immune complex induced glomerular injury in humans $[9,10]$. 
Morphologically, MPGN-I is characterised by double contouring of glomerular basement membranes, mesangial proliferation, immune complex (immunoglobulin and complement) deposition in capillary walls and mesangium, that corresponds to subendothelial and mesangial electron dense deposits [11]. MPGN-I is known to be associated with a wide spectrum of aetiologies such as autoimmune disorders and bacterial, viral and parasitic infections, and is well-recognised in hepatitis B and C viral infections [5,11]. The clinical course and management of MPGN-I hinges on identification of the underlying cause [12].

\section{Conclusions}

We describe the first well-documented occurrence of MPGN-I, as a manifestation of immune complexmediated glomerular injury in a case of DVI that presented with impaired kidney function and significant proteinuria. The patient was satisfactorily managed with appropriate immunosuppression. We emphasize the need for a proper renal biopsy diagnosis in cases of dengue fever presenting with renal dysfunction and proteinuria; the pathological diagnosis prompts appropriate management to achieve rapid clinical improvement and avoid long-term complications.

\section{Additional Information \\ Disclosures}

Human subjects: Consent was obtained or waived by all participants in this study. Conflicts of interest: In compliance with the ICMJE uniform disclosure form, all authors declare the following: Payment/services info: All authors have declared that no financial support was received from any organization for the submitted work. Financial relationships: All authors have declared that they have no financial relationships at present or within the previous three years with any organizations that might have an interest in the submitted work. Other relationships: All authors have declared that there are no other relationships or activities that could appear to have influenced the submitted work.

\section{Acknowledgements}

Acknowledgement: The authors are grateful to Kadhem Alkhenaizi of Expressmed Laboratories, Bahrain for preparing the biopsy sample.

\section{References}

1. Wellekens K, Betrains A, De Munter P, Peetermans W: Dengue: current state one year before WHO 20102020 goals. Acta Clin Belg. 2020, 1-9. 10.1080/17843286.2020.1837576

2. Lizarraga KJ, Nayer A: Dengue-associated kidney disease. J Nephropathol. 2014, 3:57-62. 10.12860/jnp.2014.13

3. Lim CT, Fuah KW, Lee SE, Kaniappan KK, Then RF: Dengue-associated acute kidney infection: an updated and comprehensive qualitative review of literature. EMJ Nephrol. 2019, 7:86-94.

4. Eswarappa M, Reddy SB, John MM, Suryadevara S, Madhyashatha RP: Renal manifestations of dengue viral infection. Saudi J Kidney Dis Transpl. 2019, 30:394-400. 10.4103/1319-2442.256847

5. Sethi S, Fervenza FC: Membranoproliferative glomerulonephritis: pathogenetic heterogeneity and proposal for a new classification. Semin Nephrol. 2011, 31:341-8. 10.1016/j.semnephrol.2011.06.005

6. Bhargava V, Gupta P, Kauntia R, Bajpai G: Dengue fever-induced thrombotic microangiopathy: an unusual cause of renal failure. Indian J Nephrol. 2017, 27:321-23. 10.4103/0971-4065.202837

7. Bhagat M, Zaki SA, Sharma S, Manglani MV: Acute glomerulonephritis in dengue haemorrhagic fever in the absence of shock, sepsis, haemolysis or rhabdomyolysis. Paediatr Int Child Health. 2012, 32:161-3. 10.1179/2046905512Y.0000000001

8. Boonpucknavig S, Vuttiviroj O, Boonpucknavig V: Infection of young adult mice with dengue virus type 2 . Trans R Soc Trop Med Hyg. 1981, 75:647-53. 10.1016/0035-9203(81)90142-5

9. Wiwanitkit V: Immune complex: does it have a role in pathogenesis of renal failure in dengue infection? Ren Fail. 2005, 27:803-4. 10.1080/08860220500244914

10. Wiwanitkit V: Dengue nephropathy: immunopathology and immune complexinvolvement. Saudi J Kidney Dis Transpl. 2016, 27:1280-1282. 10.4103/1319-2442.194693

11. Cook HT, Pickering MC: Histopathology of MPGN and C3 glomerulopathies. Nat Rev Nephrol. 2015, 11:1422. 10.1038/nrneph.2014.217

12. Khandelwal P, Bhardwaj S, Singh G, Sinha A, Hari P, Bagga A: Therapy and outcomes of C3 glomerulopathy and immune-complex membranoproliferative glomerulonephritis. Pediatr Nephrol. 2021, 36:591-600. 10.1007/s00467-020-04736-8 